\title{
PENDIDIKAN MORAL DI SEKOLAH
}

Oleh:

\author{
Rukiyati (rukiyati@uny.ac.id)
}

Fakultas Ilmu Pendidikan Universitas Negeri Yogyakarta

\begin{abstract}
Abstrak
Pendidikan moral di sekolah perlu dilaksanakan secara bersungguh-sungguh untuk membangun generasi bangsa yang berkualitas. Walaupun peran utama untuk mendidik moral anak adalah di tangan orang tua mereka, guru di sekolah juga berperan besar untuk mewujudkan moral peserta didik yang seharusnya. Keluarga, sekolah, dan masyarakat bersama-sama bertanggung jawab untuk mendidik anak-anak muda agar bermoral baik sekaligus pintar secara intelektual sehingga terwujud generasi muda yang unggul. Itulah tujuan utama pendidikan sebagaimana dinyatakan oleh Aristoteles. Pendidikan moral di sekolah harus dirancang komprehensif mencakup berbagai aspek, yaitu: pendidik, materi, metode, dan evaluasi sehingga hasilnya diharapkan akan optimal.
\end{abstract}

Kata kunci: tujuan pendidikan, nilai moral, sekolah, komprehensif.

\section{MORAL EDUCATION AT SCHOOL}

Moral education in schools needs to be carried out seriously to build a quality generation of the nation. Although the main role of educating children's morals is in the hands of their parents, teachers in schools also play a major role in realizing the moral of the students they should be. Families, schools, and communities are jointly responsible for educating young people to be morally good and intellectually smart so that they excel as a human being. That is the main purpose of education as stated by Aristotle. Moral education in schools must be designed comprehensively covering various aspects, namely: educators, materials, methods, and evaluations so that the results are expected to be optimal.

Keywords: educational goals, moral values, school, comprehensive.

\section{PENDAHULUAN}

Sekolah merupakan lingkungan mikrosistem. Bronfenbrenner (1979: 22) mengatakan bahwa mikrosistem adalah sebuah pola dari aktivitas, peran dan relasi interpersonal yang dialami oleh seseorang yang sedang tumbuh berkembang di dalam setting tertentu dengan karakteristik fisik khusus, yaitu suatu lingkungan kehidupan yang di dalamnya seorang individu menghabiskan sebagian besar waktunya, seperti keluarga, teman sebaya, sekolah dan lingkungan tetangga. Di dalam mikrosistem ini, seorang individu berinteraksi langsung dengan orang tua, 
guru-guru, teman sebaya dan yang lain. Seorang anak bukan penerima pasif dari pengalaman, tetapi bersifat interaksi timbal balik dengan yang lain dan membentuk mikrosistem masingmasing.

Sebagai sebuah mikrosistem, sekolah diperkirakan mempunyai pengaruh yang kuat yang dapat dilihat secara langsung dalam diri subjek didik. Terlebih lagi di zaman sekarang, ketika banyak orang tua menaruh harapan sangat besar terhadap sekolah untuk menjadikan anak-anaknya pintar dan baik. Sekolah yang baik merupakan keniscayaan agar pengaruhnya terhadap anak menjadi positif. Sekolah merupakan bentuk pendidikan formal.

Noeng Muhadjir (2003: 16-18) mengatakan bahwa ditinjau dari segi antropologi kultural dan sosiologi, ada tiga fungsi utama pendidikan, yaitu menumbuhkan kreativitas subjek-didik, menumbuhkembangkan nilai-nilai insani dan Ilahi pada subjek didik dan satuan sosial masyarakat, dan meningkatkan kemampuan kerja produktif pada subjek didik. Dengan kata lain, fungsi sekolah terkait dengan upaya menumbuhkan nilai-nilai akademik, nilai-nilai sosial dan nilai-nilai religius. Ketiga kelompok nilai inilah yang sekarang menjadi wacana dengan istilah yang populer: kecerdasan intelektual, kecerdasan emosional dan kecerdasan spiritual.

Sekolah yang baik adalah sekolah yang peduli dan fokus pada pendidikan moral atau pendidikan nilai di samping kegiatan pengajaran ilmu. Amstrong (2006: 17) mengemukakan teorinya tentang sekolah sebagai wahana pengembangan manusia (human development). Istilah "pengembangan” atau "development" lebih berkonotasi pada upaya menumbuhkan, memerdekakan manusia dari beban, rintangan dan kesulitan. Istilah ini juga bermakna proses yang berlangsung terus sepanjang waktu. Maka, pengembangan manusia dalam pendidikan dapat didefinisikan menjadi "keseluruhan tindakan dan komunikasi lisan dan tertulis yang melihat tujuan pendidikan lebih mengutamakan pada upaya membantu, mendorong, memfasilitasi pertumbuhan siswa sebagai manusia utuh, termasuk di dalamnya sisi kognitif, emosional, sosial, etik, kreatif dan spiritualnya

Berdasarkan pertimbangan di atas, perlu dilakukan perencanaan terkait pendidikan moral di sekolah yang bersifat komprehensif, yang melibatkan berbagai komponen: pendidik, materi, metode, dan evaluasinya. Tulisan ini akan membahas komponen pendidikan 
moral tersebut sebagai unsur penting yang harus diperhatikan agar pendidikan moral di sekolah dapat berjalan dengan lebih optimal.

\section{METODE PENELITIAN}

Tulisan ini merupakan gabungan antara teori dan hasil penelitian lapangan. Rangkuman berbagai teori diambil dari hasil pemikiran dan penelitian para pakar pendidikan moral seperti Kirschenbaum, Thomas Lickona, Darmiyati Zuchdi dan Nurul Zuriah yang kemudian diinterpretasi dan disintesiskan oleh penulis sehingga diperoleh kesatuan gagasan tentang teori pendidikan moral di sekolah. Data lapangan diperoleh dari hasil penelitian penulis (2012) di sebuah sekolah dasar Islam di Sleman yang memfokuskan pada pendidikan moral bagi siswasiswanya sebagai tujuan sekolah yang penting di samping pendidikan intelektual.

\section{HASIL DAN PEMBAHASAN}

\section{Pendidik Moral di Sekolah}

Tidak dapat dipungkiri bahwa pendidik utama di sekolah adalah guru. Walaupun demikian, perlu disadari bahwa pendidik moral di sekolah tidak terbatas pada guru semata. Di sekolah ada pegawai tata usaha, pramu kantor, tukang kebun, dan komite sekolah. Semua subjek tersebut berperan untuk bersama-sama membangun moral siswa agar menjadi orang yang baik.

Guru yang baik tentu saja sangat strategis untuk terbentuknya moral siswa yang baik pula. Sebagaimana dinyatakan oleh Henry Giroux (1988: xxxiv) sekolah berfungsi sebagai ruang publik yang demokratis. Sekolah sebagai tempat demokratis yang didedikasikan untuk membentuk pemberdayaan diri dan sosial. Dalam arti ini, sekolah adalah tempat publik bagi peserta didik untuk dapat belajar pengetahuan dan keahlian yang dibutuhkan untuk hidup dalam demokrasi yang sesungguhnya. Sekolah bukan sebagai perluasan tempat kerja atau sebagai lembaga garis depan dalam pertempuran pasar internasional dan kompetisi asing, sekolah sebagai ruang publik yang demokratis dibangun untuk membentuk siswa dapat mengajukan pertanyaan kritis, menghargai dialog yang bermakna dan menjadi agensi kemanusiaan. Peserta didik belajar wacana tentang organisasi umum dan tanggung jawab sosial. Dalam konteks inilah, guru berfungsi untuk mewujudkan peserta didik agar menjadi warga negara yang aktif dalam masyarakat yang demokratis. Hal tersebut juga diamanatkan di dalam 
tujuan pendidikan berdasarkan UndangUndang Nomor 2 Tahun 2003 tentang Sistem Pendidikan Nasional. Selain itu guru juga bertugas untuk meningkatkan keimanan dan ketakwaan serta akhlak yang mulia dalam diri peserta didik.

Oleh karena guru adalah ujung tombak untuk mewujudkan moral yang baik dalam diri peserta didik, maka guru terlebih dahulu harus bermoral baik pula. Dengan demikian, pendidikan moral yang dilaksanakan oleh guru akan lebih mudah diterima dan diteladani oleh para peserta didiknya.

\section{Materi Pendidikan Moral}

Pada intinya materi pendidikan moral mencakup ajaran dan pengalaman belajar untuk menjadi orang bermoral dalam kaitan dengan diri sendiri, moral terhadap sesama manusia dan alam semesta serta moral terhadap Tuhan Yang Maha Esa (Zuriah, 2010).

Pendidikan moral terhadap diri sendiri yang penting diberikan kepada peserta didik berkaitan dengan nilainilai kebersihan diri, kerajinan dalam belajar/bekerja, keuletan, disiplin waktu. Pendidikan moral untuk sesama manusia mencakup nilai-nilai moral sosial seperti kerjasama, toleransi, respek, berlaku adil, jujur, rendah hati, tanggung jawab, dan peduli. Pendidikan moral untuk hubungan manusia dengan alam semesta dapat diberikan dengan menguatkan nilai-nilai keseimbangan alam, menjaga kelestarian alam, tidak merusak alam, hemat, dan mendidik untuk menggunakan kembali barang-barang bekas (daur ulang) dalam bentuk yang baru. Pendidikan moral untuk hubungan manusia dengan Sang Khalik penting dilaksanakan terlebih Indonesia adalah negara yang berketuhanan Yang Maha Esa (pasal 29 UUD 1945). Indonesia berbeda dengan negara sekuler dan negara komunis. Pendidikan agama yang di dalamnya sarat dengan nilai-nilai moral diberi tempat yang khusus dan penting. Nilai-nilai moral yang diajarkan di dalam ajaran agama menjadi sumber nilai bagi kehidupan masyarakat Indonesia sehingga di sekolah pun nilainilai moral agama tetap diberi tempat khusus sebagaimana telah dimasukkan dalam kurikulum, baik intra maupun ekstra kurikuler. Hanya saja perlu diwaspadai nilai-nilai moral agama harus dibarengi dengan sikap untuk tetap bertoleransi. Demikian itu dinyatakan oleh Sukarno (Bahar, 1995: 16) sebagai ketuhanan yang berkebudayaan, yaitu ketuhanan dengan dasar toleransi, tidak ada egoisme agama. 
3. Metode Pendidikan Moral

Kirschenbaum (1995:

mengusulkan 100 cara atau metode pendidikan moral, yang dipayungi dalam lima kategori besar metode pendidikan moral yaitu penanaman (inkulkasi) nilai-nilai dan moralitas, modeling nilainilai dan moralitas, fasilitasi nilai-nilai dan moralitas, kecakapan untuk mengembangkan nilai dan melek moral, pelaksanaan program pendidikan nilai di sekolah.

Pendidikan moral pada masa sekarang menghadapi berbagai tantangan seiring dengan kemajuan zaman yang ditandai oleh keterbukaan informasi dan kecanggihan teknologi. Hal ini tentu berbeda sekali dengan masa lalu. Di lingkungan masyarakat religius tradisional, moral diwariskan kepada generasi berikutnya secara given yaitu indoktrinasi. Artinya suatu ajaran moral harus diterima karena memang sejak dahulu diajarkan demikian. Setelah itu, ajaran tersebut dilaksanakan. Peran akal sebatas berupaya memahami alasannya dan konsekuensinya.

Anak-anak yang hidup sekarang ini hidup di zaman modern akhir yang sangat jauh berbeda cara berpikir dan perilakunya dengan anak-anak di masa lalu. Indoktrinasi dipandang para ahli sebagai metode yang sudah usang dan tidak sejalan dengan semangat modern tersebut. Maka, ada metode lain yang lebih sesuai yaitu inkulkasi atau penanaman nilai.

a. Inkulkasi nilai

Metode ini dapat dilaksanakan dalam pembelajaran moral di sekolah maupun di dalam keluarga dengan berbagai cara. Kirschenbaum mengetengahkan 34 cara inkulkasi nilai, di antaranya adalah identifikasi nilainilai target, membaca buku-buku sastra dan non-fiksi, bercerita.

Program pendidikan moral dengan cara inkulkasi nilai dimulai dengan mengidentifikasi secara jelas nilai-nilai apa yang diharapkan akan tertanam dalam diri subjek didik. Hasilnya adalah “nilai-nilai target” yang akan dicapai dalam program pendidikan moral. Misalnya, Baltimore County Public Schools mengidentifikasi “nilai-nilai inti” bagi sekolah mereka (sekolah dasar), yaitu: keramahan, kejujuran, tanggung jawab, warga negara yang bertanggung jawab, toleransi, patriotisme, belas kasih.

Kementerian Pendidikan Kanada menyusun nilai-nilai target bagi tingkat sekolah dasar dan SMP yaitu: belas kasih, kerja sama, sabar, damai, ramah, kebebasan, murah hati, jujur, adil, setia, 
moderat, menghargai lingkungan hidup, menghargai orang lain, menghargai diri sendiri, tanggung jawab, disiplin diri, peka, toleransi.

Membaca buku-buku sastra (novel, cerpen, dsb) dan non-fiksi (biografi, kisah perjalanan/petualangan, dsb) dapat menjadi salah satu cara ampuh untuk menanamkan nilai-nilai dan moralitas dalam diri subjek didik. Misalnya, Diary of a Young Girl, karya Anne Frank yang ditulis dalam persembunyiannya ketika zaman Nazi mengandung pembelajaran moral yang sangat kuat tentang belas kasih dan toleransi. Setelah membaca buku-buku tersebut, guru dan siswa dapat mengungkapkan nilai-nilai dan masalah-masalah moral yang terdapat di dalam bacaan tersebut.

Memberikan buku-buku yang bermutu, buku cerita dan artikel untuk dibaca para siswa adalah cara yang mudah dan penting untuk membangun nilai moral dalam diri siswa, disamping juga akan meningkatkan tujuan pembelajaran secara akademik.

Strategi lainnya adalah dengan bercerita (story telling) dimulai dari rumah atau keluarga, tetapi dapat juga dilakukan di sekolah, terutama di sekolah-sekolah dasar. Pada zaman dahulu, sebelum tidur anak-anak diceritakan kisah-kisah yang ajaib dari negeri dongeng sebagai pengantar tidur sekaligus pendidikan moral. Biasanya cerita-cerita tentang binatang seperti $\mathrm{Si}$ Kancil dan Buaya, Si Kancil dan Kera, Si Kancil dan Kura-kura, dsb. Juga ada cerita-cerita seperti Putri Salju, Ciung Wanara, Jaka Tarub yang semuanya mengajarkan kebaikan. Juga ada ceritacerita heroisme atau kepahlawanan tokoh-tokoh besar dalam sejarah yang dikagumi dan patut dijadikan teladan. Bercerita juga dapat dilakukan guru di sekolah dengan tidak kalah menarik dari orang tua siswa. Terlebih lagi di sekolah, media untuk bercerita dapat dibuat bersama-sama antara guru dan siswa sehingga pembelajaran yang dihasilkan lebih mencapai banyak sasaran dan keterampilan serta lebih kreatif. Kirschenbaum mengatakan bahwa metode bercerita merupakan metode yang sangat akurat ditinjau dari perspektif historis, yaitu membangun makna dan menanamkan nilai-nilai yang diinginkan, keyakinan moral, dan karakter yang diinginkan dalam diri pendengarnya (peserta didik).

\section{b.Metode keteladanan}

Keteladanan merupakan bentuk mengestafetkan moral yang digunakan oleh masyarakat religius tradisional, dan digunakan pula oleh masyarakat modern 
sekarang ini. Dalam masyarakat tradisional, keteladanan diterima secara terberi tanpa harus mengejar argumentasi rasionalnya; sedangkan pada masyarakat modern sekarang keteladanan diterima dengan pemahaman dan argumentasi rasional (Muhadjir, 2004: 163). Orang tua dan guru merupakan sosok yang harus memberikan teladan baik kepada subjek didik. Anak-anak lebih mudah meniru perilaku dari pada harus mengingat dan mengamalkan kata-kata yang diucapkan oleh orang tua dan guru.

\section{c. Metode klarifikasi nilai}

Dalam masyarakat liberal, moral diperkenalkan lewat proses klarifikasi, penjelasan agar terjadi pencerahan pada subjek didik. Seberapa jauh sesuatu moral diterima oleh anak, sangat ditentukan oleh anak itu sendiri. Anak diberikan kebebasan untuk memutuskan sendiri. Pendekatan klarifikasi nilai adalah salah satu contoh yang memberikan kebebasan untuk anak menentukan nilai-nilainya. Sebagaimana dinyatakan oleh Sidney B. Simon, dkk (1974: 6) bahwa pendekatan klarifikasi nilai mencoba untuk membantu anakanak muda menjawab beberapa pertanyaan dan membangun sistem nilai sendiri. Di dalam bukunya: Values
Clarification, Simon menjelaskan 79 strategi klarifikasi nilai yang dapat diterapkan, khususnya oleh para guru di sekolah. Strategi-strategi yang disajikan di dalam buku tersebut disusun oleh Louis Raths yang diturunkan dari pemikiran John Dewey. Berbeda dengan pendekatan teoritis yang lain, Raths tidak mempermasalahkan isi dari nilainilai yang dimiliki seseorang, tetapi lebih memperhatikan proses penilaian. Fokusnya adalah bagaimana orang sampai pada keyakinan tertentu yang dipegangnya dan membentuk pola perilaku tertentu.

Di Indonesia, strategi klarifikasi nilai telah diperkenalkan sejak tahun 1980-an dan banyak para pendidik yang mengkritik dan menolaknya. Hal-hal yang tidak dapat diterima, adalah yang terkait dengan pilihan anak, misalnya anak dibiarkan tidak mendirikan salat, sebelum anak sadar akan pentingnya salat. Jika dibiarkan, maka dikhawatirkan anak tidak akan melakukan salat sampai ia dewasa.

\section{d. Metode fasilitasi nilai}

Guru dan pihak sekolah memberikan berbagai fasilitas yang dapat digunakan siswa agar dapat merealisasikan nilai-nilai moral dalam dirinya baik secara individu maupun 
berkelompok, misalnya fasilitas beribadah berupa mesjid dan mushola, fasilitas membuat kompos dari sampah sekolah, fasilitas berupa ruang diskusi, perpustakaan dengan buku-buku cerita yang memuat nilai-nilai moral, dan sebagainya.

Di sebuah sekolah dasar Islam terpadu di Sleman, di samping fasilitas umum yang telah banyak disediakan oleh berbagai sekolah, terdapat pula fasilitasi sarana prasarana kegiatan luar kelas yang menjadi prioritas utama untuk pengembangan moral dan kecakapan hidup anak seperti fasilitas untuk meluncur (flying fox), fasilitas panjat tebing, fasilitas pohon-pohon tanaman keras (untuk latihan memanjat). Kesemuanya disiapkan untuk latihan percaya diri, keberanian, bersyukur, dan rendah hati.

e. Metode keterampilan nilai moral

Keterampilan moral dalam diri peserta didik dapat diwujudkan dimulai dengan pembiasaan. Lama kelamaan pembiasaan itu ditingkatkan dengan cara peserta didik merancang sendiri berbagai tindakan moral yang akan diwujudkan sebagai suatu komitmen diri, action plan mereka sendiri sebagai wujud realisasi diri menjadi orang yang baik dan memperoleh hidup yang bermakna.
Kantin kejujuran, berbagai kegiatan sosial yang dirancang oleh siswa di sekolah adalah contoh-contoh dari metode keterampilan nilai yang selama ini telah banyak dilakukan di sekolahsekolah menengah. Hanya saja, perlu dikembangkan juga keterampilan nilai ini untuk diterapkan oleh guru-guru di sekolah dasar.

\section{Evaluasi Pendidikan Moral}

Di samping keempat aspek (isi, metode, proses dan pendidik), pendidikan nilai juga memerlukan evaluasi yang komprehensif. Evaluasi dilakukan untuk mengetahui ketercapaian tujuan. Tujuan pendidikan nilai meliputi tiga kawasan, yakni penalaran nilai/moral, perasaan nilai/moral dan perilaku nilai/moral. Maka, evaluasi pendidikan nilai juga mencakup tiga ranah tersebut. berupa evaluasi penalaran moral, evaluasi karakteristik afektif, dan evaluasi perilaku (Darmiyati, 2009: 51).

Supaya tujuan pendidikan nilai yang berwujud perilaku yang diharapkan dapat tercapai, subjek didik harus sudah memiliki kemampuan berpikir/bernalar dalam permasalahan nilai/moral sampai dapat membuat keputusan secara mandiri dalam menentukan tindakan apa yang harus dilakukan. 
Dalam hal evaluasi afektif, Dupon (Darmiyati, 2009: 54) telah menemukan tahap-tahap perkembangan afektif sebagai berikut:

a. Impersonal, egocentric: tidak jelas strukturnya.

b. Heteronomous: berstruktur unilateral, vertikal.

c. Antarpribadi: berstruktur horizontal, bilateral.

d. Psychological-personal: menjadi dasar keterlibatan orang lain atau komitmen pada sesuatu yang ideal.

e. Autonomous: didominasi oleh sifat otonomi.

f. Integritous: memiliki integritas, mampu mengontrol diri secara sadar.

Selanjutnya, dikatakan oleh Darmiyati bahwa untuk menentukan seseorang berada pada tahap perkembangan afektif yang mana, Dupont menggunakan instrumen yang menuntut adanya respons yang melibatkan perasaan.

Selain itu, ada juga pengukuran dengan menggunakan skala sikap seperti yang dikembangkan oleh Likert atau Guttman dan semantic differential yang dikembangkan oleh Nuci, dan peneliti lainnya. Walaupun dinamakan skala sikap, karakteristik afektif yang dievaluasi dapat pula mencakup minat, motivasi, apresiasi, kesadaran akan harga diri dan nilai.

Cara mengevaluasi capaian belajar dalam ranah afektif dapat dilakukan dengan mengukur afek atau perasaan seseorang secara tidak langsung, yaitu dengan menafsirkan ada atau tidaknya afek positif (atau negatif) yang muncul dan intensitas kemunculan afek dari tindakan atau pendapat seseorang.

Di antara skala pengukuran yang ada, skala Likert paling banyak digunakan, sebab relatif lebih mudah pengembangannya dan dapat memiliki reliabilitas yang tinggi. Skala Likert telah diadaptasi dengan sukses untuk mengukur berbagai karakteristik afektif.

Evaluasi pendidikan moral sebenarnya yang terakhir dan sangat penting adalah perilaku. Perilaku moral sangat sulit untuk dievaluasi. Perilaku moral hanya mungkin dievaluasi secara akurat dengan melakukan observasi (pengamatan) dalam jangka waktu yang relatif lama dan secara terus-menerus. Dari pengamatan tersebut dapat ditarik kesimpulan apakah perilaku orang yang diamati telah menunjukkan watak atau kualitas akhlak yang akan dievaluasi. Misalnya, apakah orang tersebut benarbenar jujur, adil, memiliki komitmen, beretos kerja, tanggung jawab, dan sebagainya. Pengamat harus orang yang 
sudah mengenal orang-orang yang diobservasi agar penafsirannya terhadap perilaku yang muncul tidak salah (Darmiyati, 2009: 55).

Terkait dengan evaluasi pendidikan moral, dalam teori pendidikan Islam juga menitikberatkan pada evaluasi sikap dan perilaku. Samsu Nizar (2002: 80) mengatakan bahwa evaluasi pendidikan Islam secara keseluruhan lebih ditujukan untuk mengetahui penguasaan sikap dan perilaku dari pada penguasaan aspek kognitif. Penekanan ini bertujuan untuk mengetahui kemampuan subjek didik yang meliputi empat hal, yaitu:

a. Sikap dan pengalaman peserta didik terhadap hubungan pribadinya dengan Tuhannya;

b. Sikap dan pengalaman peserta didik terhadap arti hubungan dirinya dengan masyarakat;

c. Sikap dan pengalaman peserta didik terhadap arti hubungan kehidupannya dengan alam sekitarnya;

d. Sikap dan pandangan peserta didik terhadap diri sendiri selaku hamba Allah, anggota masyarakat, serta khalifah Allah SWT.

Keempat kemampuan dasar tersebut dijabarkan dalam beberapa klasifikasi kemampuan teknis, yaitu: a. Bagaimana loyalitas dan pengabdian peserta didik kepada Allah dengan indikasi-indikasi lahiriah berupa tingkah laku yang mencerminkan keimanan dan ketakwaan kepada Allah SWT;

b. Bagaimana penerapan nilai-nilai keagamaan dalam kegiatan kehidupan bermasyarakat, seperti akhlak yang mulia dan disiplin;

c. Bagaimana peserta didik mengelola, memelihara serta menyesuaikan diri dengan alam sekitarnya, termasuk di dalamnya apakah ia merusak atau memberi makna bagi kehidupannya dan masyarakat di sekitarnya;

d. Bagaimana peserta didik memandang dirinya sendiri sebagai hamba Allah dalam menghadapi kenyataan masyarakat yang beraneka ragam budaya, suku dan agama.

\section{KESIMPULAN}

Dari uraian yang telah dikemukakan, dapat disimpulkan bahwa pendidikan moral di sekolah penting dilakukan oleh guru dan segenap komponen warga sekolah agar tercapai pendidikan moral yang komprehensif. Komponen-komponen pendidikan moral di sekolah yang lain yang tidak kalah penting adalah cakupan materi, variasi metode, dan evaluasi yang menyeluruh. 
Dengan memperhatikan komponenkomponen tersebut, sekolah dengan guru sebagai peran utama dapat merancang pendidikan moral secara lebih komprehensif sehingga hasilnya dapat dicapai secara optimal, yaitu berkembangnya nilai-nilai moral dalam diri peserta didik sehingga mereka menjadi generasi muda yang berkualitas.

\section{DAFTAR PUSTAKA}

Armstrong, Thomas. 2006. The Best School. Virginia: Association for Supervision and curriculum Development.

Bronfenbrenner, Urie. (1979). The ecology of human developmentExperiments by nature and design. Diambil pada tanggal 18 Januari 2010 dari books.google.co.id

Darmiyati Zuchdi. (Juli 2008). Potret pendidikan karakter di berbagai jenjang sekolah. Proceding Seminar dan Lokakarya Nasional Restrukturisasi Pendidikan Karakter. Universitas Negeri Yogyakarta, Yogyakarta. . (2009). Humanisasi pendidikan - Menemukan kembali pendidikan yang manusiawi. Jakarta: Bumi Aksara.

Davidson, Matthew, et.al. (2007). Smart and good schools. Education week, November 2007. Diambil pada tanggal 3 Maret 2008 dari: http://www.edweek.org/ew/articl $\underline{\text { es/2007 }}$
Giroux, Henry A. (1988). Teachers as Intellectual - toward a critical pedagogy of learning New York: Bergin \& Garvey.

Kirschenbaum, Howard. (1995). 100 Ways to Enhance Values and Morality in Schools and Youth Settings. Boston: Allyn and Bacon.

Lickona, Thomas. (1991). Educating for character - How our schools can teach respect and responsibility. New York: Bantam Books.

Lovat, Terry. (2009). Values education and quality teaching: two sides of learning coin. Dalam Terry Lovat \& Ron Toomey (Eds.) Values education and quality teaching. [versi elektronik]. Diambil pada tanggal 15 Januari 2010 dari www.springer.com

Noeng Muhadjir. (2003). Ilmu pendidikan dan perubahan sosial. Yogyakarta: Rake Sarasin.

Rukiyati. (2012). Pendidikan nilai holistik untuk membentuk karakter siswa di SDIT Nurul Islam Yogyakarta. Jurnal Cakrawala Pendidikan. Penerbit: Lembaga Penelitian dan Pengabdian pada Masyarakat Universitas Negeri Yogyakarta: Edisi Khusus. Mei 2012.

Simon, Sidney B. dkk. (1978). Values clarification - a Handbook of practical strategies for teachers and students. Revised Edition. New York: Hart Publishing Company, Inc. 